\title{
Corrosion failures of austenitic and duplex stainless steels in a biodiesel plant
}

\author{
${ }^{1}$ Petrobras, Avenue of Industries 531, CEP: 39404000, Montes Claros, MG, Brazil, \\ ${ }^{2}$ Chemical Engineering Department, Federal University of Minas Gerais, Antonio Carlos Avenue 6627, CEP: 31270901, \\ Belo Horizonte, MG, Brazil. \\ e-mail: carloseduardotorres@petrobras.com.br, thalys_eduardo@hotmail.com, vlins@deq.ufmg.br
}

\begin{abstract}
The neutralization of catalysts with hydrochloric acid is an important step in a biodiesel process which generates steel corrosion due to the decrease in $\mathrm{pH}$, and the addition of chlorides in the medium. Other factor responsible for corrosion and consequently failures is the poor miscibility between biodiesel and acid water generating a heterogeneous coverage of the surface of the pipelines and equipment by biodiesel and acid water, presence of galvanic cells and localized corrosion. In this paper, corrosion failures of AISI 316L and 904L austenitic stainless steels (SS), and of SAF 2205, 2507 duplex SS in a biodiesel plant were identified and studied. The low $\mathrm{pH}$, presence of chlorides, high thermal input in welding, temperature gradient and mainly proximity to the acid injection site play the major roles in corrosion which generate the studied failures. Corrosion failures occurred in pipes transporting biodiesel and acid water, in a spool of acid water injection, in a static biodiesel mixer with acidic water, in a cylindrical decanter vessel, and in heat exchangers.
\end{abstract}

Keywords:Chloride; Corrosion; Pipeline failures; Process-plant failures; Welds

\section{INTRODUCTION}

Biofuel has replaced fuels derived from petroleum or natural gas in combustion engines or in other types of energy generation all around the world [1,2]. A sustainable supply of agricultural feedstock for biofuel production is viable in China as reported by Ye et al. [3]. In India [4], liquid biofuel production has been promoted as a rural development strategy. Biofuels are regarded as one of the most viable options for reduction of $\mathrm{CO}_{2}$ emissions in the transport sector in Finland [5]. Oh et al. [6] described the challenges and prospects for future development of eco-friendly and economically advanced biofuel production processes.

Biodiesel consists mainly of triacylglycerols [7] and can be obtained by transesterification [8] through a methyl route with homogeneous basic catalysis. A reaction between the triglyceride (vegetal oil or adipose) and alcohol (methanol) with an alkaline catalyst occurs at $64^{\circ} \mathrm{C}$, at atmospheric pressure, and is accompanied by sedimentation, neutralization, washing, distillation and filtration resulting in biodiesel and glycerin as coproduct [9]. Alkali-catalyzed transesterification is a most commonly used process for oils with low free fatty acids and low moisture content [9]. The neutralization of catalysts with hydrochloric acid is an important step in biodiesel process that generates steel corrosion.

In Brazilian biodiesel plants, the material used in most equipment and piping in transesterification region is the AISI 316L stainless steel (SS) which substituted the AISI 304L SS. The corrosion of steel equipment is an important concern in biofuel production plants as during biodiesel storage, transportation, and utilization [10]. The failures, which occur due to corrosion, impair the operational reliability which causes production and economic losses.

Corrosion of stainless steels in media containing chlorides is extensively studied in literature [11-15]. But this study has a novelty aspect of describing corrosion failures in a very specific medium consisting of a biodiesel and acid water where the proximity to the acid injection site plays a crucial role in the corrosive process and failure. Ferreira et al. [16] studied the orthogonal, diagonal and elbow geometric arrangements of injection of acid solution used in a biodiesel plant and proved that the elbow geometry presents the lowest 
values of chloride wall concentration, gradient of chloride mass fraction, and shear stress on the walls, coherent behavior with the geometric arrange of an emissary tube that protects the walls of external pipe against direct contact of the acid injection. The three Brazilian biodiesel plants studied in this work adopted the diagonal geometric arrangement of acid solution injection, which generate corrosion failures. Presently, the Brazilian biodiesel industries are implementing the elbow geometry with an emissary tube. Among the three geometric arrangements evaluated by Ferreira et al. [16] by using computational fluid dynamics investigation, the diagonal geometry presents the highest chloride concentration on the pipe walls and chloride mass concentration gradient.

The objective of this work is to present corrosion failures of austenitic and duplex steels in an industrial biodiesel plant and discuss the variables involved in corrosion mechanism, related to the poor miscibility between biodiesel and acid solution.

\section{FAILURE ANALYSIS}

The analysis of the history of failures occurred in Brazilian biodiesel plants included the evaluation of operation and maintenance records, covering the period between January 2010 and January 2012, with a view to mapping, from the point of view of corrosion, the critical points of failure occurrences in the process. It is estimated that at least $65 \%$ of the corrosion failures registered at three biodiesel plants in the period were analyzed. For better visualization and correlation with the process, the percentage of failures of each section is identified in the flowcharts of Figures 1 (biodiesel circuit) and 2 (glycerin circuit). The percentages were calculated in relation to all failures, considering both circuits. Of the total analyzed failures, $45.5 \%$ occurred in the biodiesel circuit and $54.5 \%$ in the glycerin circuit.

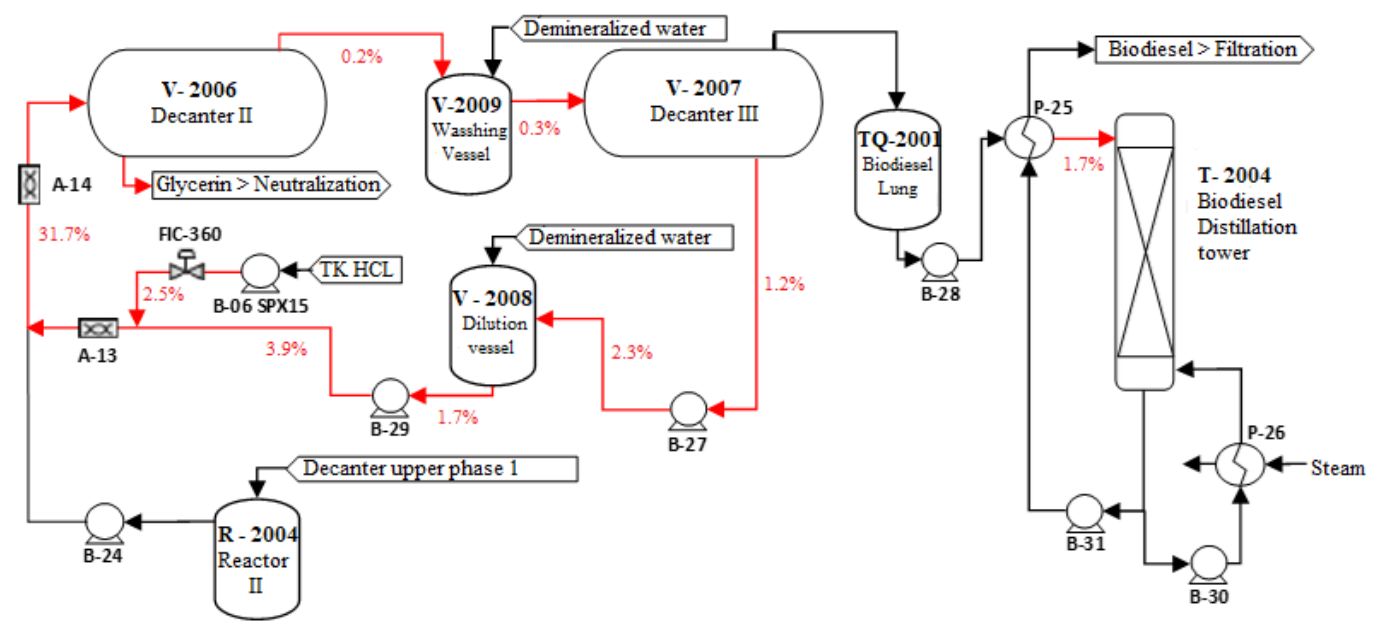

Figure 1: Flowchart with the percentage of failures of each section of the biodiesel circuit. 


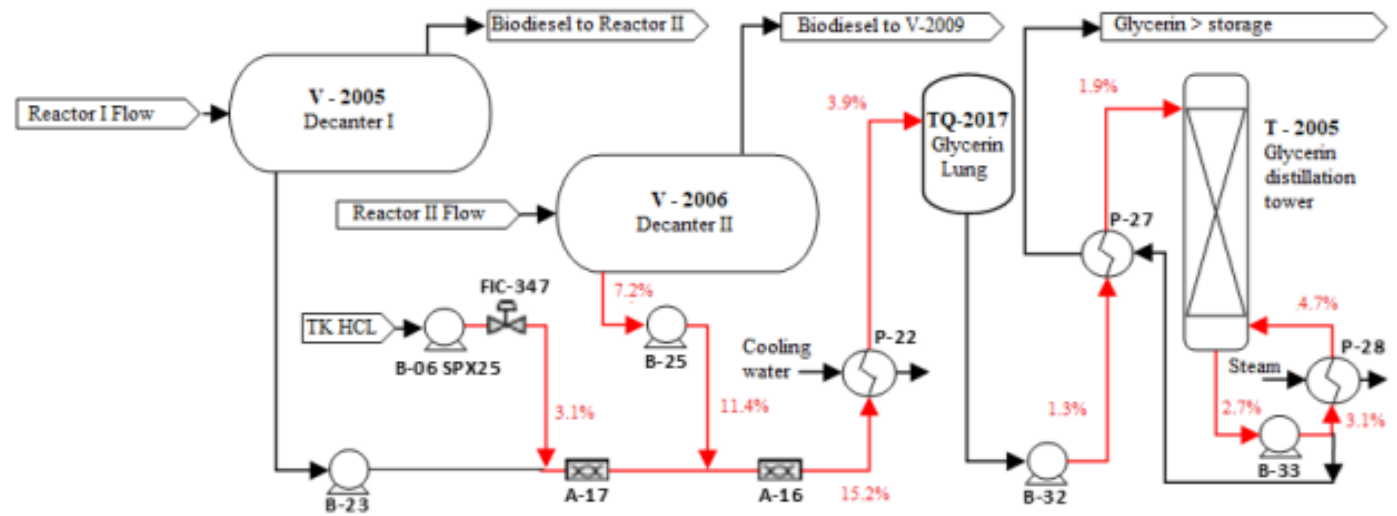

Figure 2: Flowchart with the percentage of failures of each section of the glycerin circuit.

In both circuits, there is a clear trend of decreasing the percentage of failures as the distance of the hydrochloric acid solution dosage points increases. In the biodiesel circuit, $83.7 \%$ of the failures occurred in the pipelines immediately connected to the dosing point. In the glycerin circuit, the percentage was $54.5 \%$. The lower percentage in the glycerin circuit is related to the effect of the temperature in the corrosive process, as $19.3 \%$ of the failures of this circuit occurred at the reflux of the P-28 exchanger, where the temperature is approximately $95^{\circ} \mathrm{C}$, significantly higher than $69^{\circ} \mathrm{C}$ from the region close to the acid dosage.

Although variations of the flow in relation to the set point in the acid dosage can be compensated operationally without any relevant impact to the products, transient overdoses can generate process streams with a high $\mathrm{HCl}$ concentration gradient favoring the development of corrosive processes. The performance of the acid dosing system influences not only the reaction and the quality of the product but also the integrity of the equipment.

In addition to the analysis of the history of failures, the field evaluation contemplated the study of corrosion cases registered in the power plants, comprising the period between January 2010 and June 2016. The failure history evaluation demonstrates the direct relationship between corrosion failures and the neutralization step of hydrochloric acid process streams.

Failures described in this work are of the equipment made of AISI 316L, 904L stainless steels, and SAF 2205 and 2507 duplex stainless steels. The chemical composition of alloys is shown in Table 1.

Table 1: Chemical composition (wt.\%) of alloys.

\begin{tabular}{ccccccc}
\hline AISI & UNS & $\mathrm{C}$ & $\mathrm{Cr}$ & $\mathrm{Ni}$ & $\mathrm{Mo}$ & $\mathrm{N}$ \\
\hline 316L & S31603 & 0.03 & 16.46 & 9.99 & 2.03 & 0.1 \\
904L & N08904 & 0.02 & 19.99 & 24.57 & 4.22 & 0.1 \\
2205 & S31803 & 0.015 & 22.43 & 5.34 & 2.67 & \\
2507 & S32750 & 0.02 & 25.0 & 7.1 & 4.0 & \\
\hline
\end{tabular}

Figure 3 identified the failures which occurred in circuits of biodiesel. In the biodiesel circuit, four failures (numbers 1, 2, 3, and 4) were identified before and after the A-14 mixer and were associated with the acid dosing system. Miscibility between biodiesel and acid water is poor. When the acid water stream enters the pipe, the pipe surface was wetted with biodiesel and comes in contact with acid water in some areas, creating electrochemical cells with different potentials. Failures 5 and 6 occurred in a decanter vessel in biodiesel circuit (Fig. 3). 

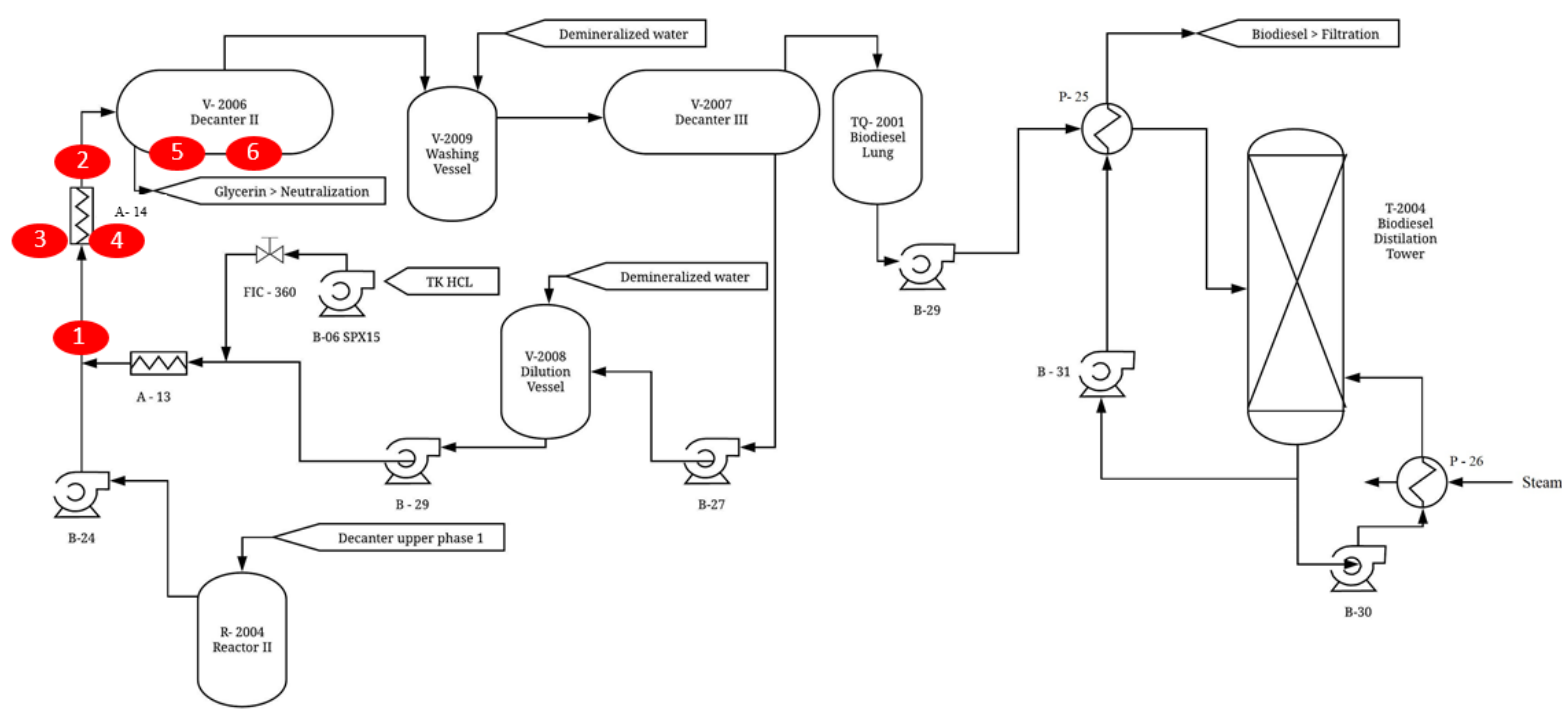

Figure 3: Identification of failures in the flowchart of the biodiesel circuit.

The failure number 1 (Fig. 4a) occurred after 23 months of plant operation, in a welded pipe of AISI 904L (25.4 mm in diameter) which transports acidic water with 1.5-2.0 vol. \% hydrochloric acid in the biodiesel plant. The conditions of medium were $\mathrm{pH}$ between 3.0 and 4.0 , temperature at $69^{\circ} \mathrm{C}$, and mass flow between 575 and $950 \mathrm{~kg} / \mathrm{h}$. The failure characteristic was a loss of metal resulting in pass-through (hole) adjacent to the weld bead (fitting) of the pipe assembly, with loss of tightness. The morphology of acid corrosion was a pitting corrosion, and crevice corrosion (region of welded joint). The main failure causes identified was welding procedure with high thermal input, and lack of sealing of the weld fitting point, forming a crevice region. The high thermal input may have caused the grain growth near the welding bead, a region that has become cathodic; the anode being the region farthest from the welding bead with smaller grains [17].

According to critical crevice solution (CCS) theory, the initiation of active crevice corrosion involves the development of a deaerated, acidic solution within the occluded geometry [18]. Oxygen reduction usually occurs in aerated area, external to the occluded region, and metal dissolution occurs in the crevice region. Metal ions attract chloride ions, forming $\mathrm{FeCl} 2$ which hydrolyzes generating hydrogen ions, acidifying the site, which also occurs inside the pits [17]. Metal ions from the steel dissolution such as Cr3+ can also undergo hydrolysis generating hydrogen ions [17]. Another possibility is the occurrence of concentration cell, in metals or metal alloys immersed in electrolytes, where the crevice region becomes saturated in metallic ions becoming the cathodic region [17]. Concerning to pitting corrosion, the pitting process progresses from pit initiation by passive film breakdown to early stages of pit growth: from metastable pitting to stable pit growth [19]. Frankel et al. [19] proposed that pit stability considerations are the controlling step of corrosion under aggressive conditions (harsh electrolytes and extreme environments and/or susceptible microstructures) and the passive film properties and protectiveness are the critical factors in less extreme environments and/or for less susceptible alloys. In this case, due to the nobility of superaustenitic steel (AISI 904L), which contains 24.57 wt. $\% \mathrm{Ni}$ and $4.22 \mathrm{wt} . \% \mathrm{Mo}$, the controlling stage of corrosion can be the passive film breakdown. However, at this point of failure number 1, which is just after the entry of the acid water into the biodiesel stream, the corrosion was aggravated by the establishment of cells on the pipe surface which was wetted with biodiesel and started to present regions in contact with the acidic water. 


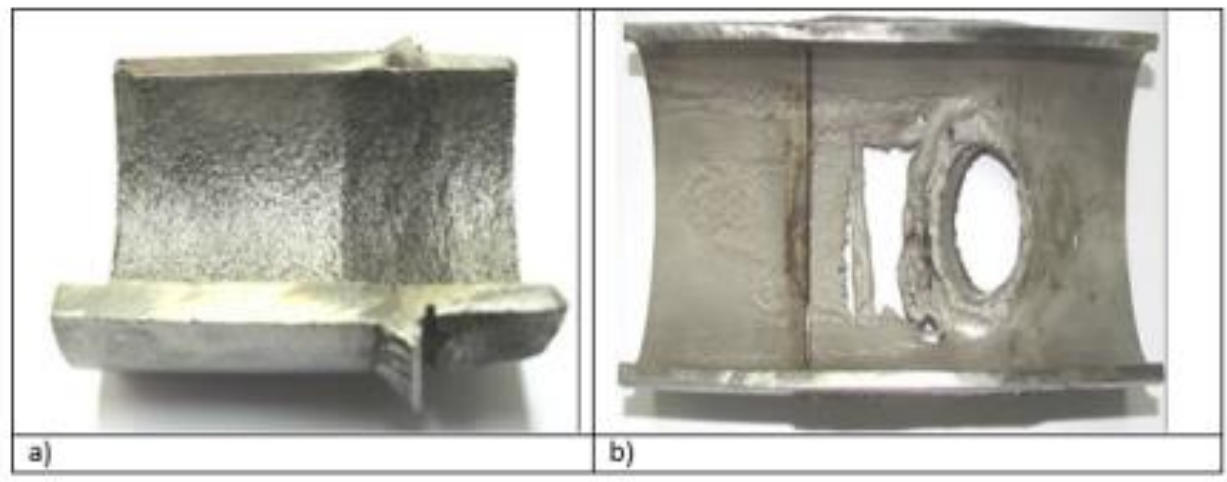

Figure 4: Corrosion of pipe made of AISI 904L (a) and spool made of AISI 904L (b).

The failure number 2 (Fig. 4b) occurred after 29 months of operation in a spool of acid water injection, made of AISI 904L SS, $50.8 \mathrm{~mm}$ in diameter, in biodiesel stream. Fluids in contact with the equipment were biodiesel, and acidic water $(1.5-2.0$ vol. \% $\mathrm{HCl})$, at $69 \mathrm{oC}$, $\mathrm{pH}$ of $3.0-5.5$, and mass flow of $8.5-15.0 \mathrm{t} / \mathrm{h}$. Loss of metal occurred resulting in the pass-through (hole) in the pipe wall downstream of the insertion of the neutralization stream, and adjacent to the weld bead of the pipe assembly. Morphology of acid corrosion was generalized, and localized at the welded joint, accelerated by the high chloride ion concentration gradient due to the heterogeneity of the flow in the region. Inefficient configuration (diagonal geometry) of the neutralization current insertion spool in the biodiesel stream was identified. Mixer A-14 (Fig. 3) was not efficient for the complete mixing between biodiesel and acid water. The $\mathrm{pH}$ is not neutralized efficiently for the orthogonal and diagonal geometries used in acid dosing systems in biodiesel plants even at $1.50 \mathrm{~m}$ the downstream point of insertion of acid solution [16]. Thus, even after the mixer A-14 (Fig. 3), chloride concentration gradients were still observed in the regions close to the pipe wall. The chloride concentrations remain high on the walls of the orthogonal and diagonal geometries in a long straight direction on the same side of acid injection [16]. Some regions of the tube remain wetted with biodiesel containing low chloride concentration and others were into contact with acidic water with high concentration of chloride. The diagonal geometry used in acid dosing system presented evidence of a weak mixture between the polar and non-polar species, even under turbulent flow as reported by Ferreira et al. [16]. The elbow geometry is more effective to reduce the local corrosive attack compared to two other simulated geometries [16].

The failure number 3 was detected in a static biodiesel mixer with acidic water shown in Figure 5a. The function of equipment is to mix the mainstream (process biodiesel) with a load of hydrochloric acid. The mixer was fabricated with a shirt of AISI 316L SS with an internal side in SAF 2205 stainless steel. The process parameters were temperature at $64.0^{\circ} \mathrm{C} ; \mathrm{pH}$ from 4.0 to 6.0 ; mass flow of $104 \mathrm{~kg} / \mathrm{h}$. Failure was caused by severe weight loss. The detection mode was performed by inspection routine (internal visual). The failure mechanism was of electrochemical corrosion in an acid medium accelerated by the operating conditions of the mixer which provide the unremitting removal of the metal ions generated on the metal surface. The root cause detected was ineffectiveness in the acid dosing system (control), and the consequence of failure was operational efficiency loss. The acid medium containing chlorides, the process temperature above the room temperature, the fluid turbulence contributed to the corrosion of steel. But the fact that the steel was in contact with a heterogeneous fluid, being regions of the surface of the equipment in contact with the biodiesel and other regions in contact with the acid water accelerated the process and generated the mass loss observed [16]. 


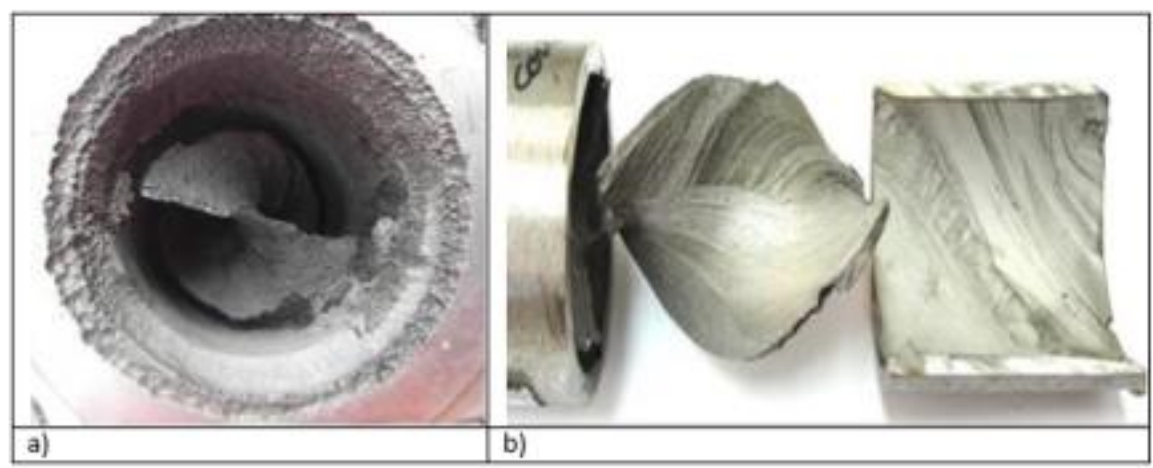

Figure 5: Corrosion of a static biodiesel mixer with acidic water (a), and corrosion of a static mixer made of AISI 316L SS with an internal helical made of SAF 2205 duplex steel (b).

The failure number 4 (Fig. 5b) occurred in a static mixer made of AISI 316L SS, $50.8 \mathrm{~mm}$ in diameter, with an internal helical made of SAF 2205 duplex steel. The function of equipment is to mix the acid water and biodiesel. The mass flow of fluid is $6.0-11.5 \mathrm{t} / \mathrm{h}, \mathrm{pH} 4.5-6.5$, at $69{ }^{\circ} \mathrm{C}$. Failure occurred after 29 months of operation. Corrosion was in an acid medium, with characteristics of the forms generalized and crevice corrosion (between the jacket and the internal helical). Mechanism of crevice corrosion was discussed earlier. The main cause of this failure was ineffectiveness of the acid dosing system; therefore, reduction of efficiency occurred with an increase of specific consumption of catalyst. Again, due to the heterogeneity of the fluid, part of the equipment encountered the apolar biodiesel fluid and part of the surface of the equipment was in contact with the polar acid water, of lower $\mathrm{pH}$ and with a higher concentration of chloride ions as described by Ferreira et al. [16].

The failure number 5 (Fig. 6) occurred, after 62 months of operation, in a cylindrical decanter vessel, with a diameter of $2.286 \mathrm{~mm}, 7.94 \mathrm{~mm}$ in thickness, with rounded tops, made of AISI 904L SS. The function of this equipment is to separate the biodiesel and glycerin phases downstream of the second reaction. The bottom phase was acid glycerin, and the top phase was biodiesel, at $69^{\circ} \mathrm{C}$, pH of $1.5-2.0$ (lower phase), and mass flow of $6.0-11.5 \mathrm{t} / \mathrm{h}$. Loss of metal resulted in the discontinuity adjacent to the weld bead of the vessel in the inferior generator of the equipment (acid phase). Corrosion was in an acid medium, with characteristics of alveolar forms concentrated in welding bead. One identified cause is a less noble consumable used, an alloy with 22 wt.\% $\mathrm{Cr}$ and 7 wt.\% Ni, in relation to the AISI 904L steel, which contains 19.99 wt.\% $\mathrm{Cr}$ and 24.57 wt.\% Ni. Corrosion in boundary region of welding bead identified in Fig. 7 was probably due to the chemical composition difference between the consumable and the base metal. Ineffectiveness of the acid dosing system, and production halts without proper acid phase drainage also contributed to the corrosion damage. Fragility of the equipment with reduction of its useful life was a consequence of this failure.

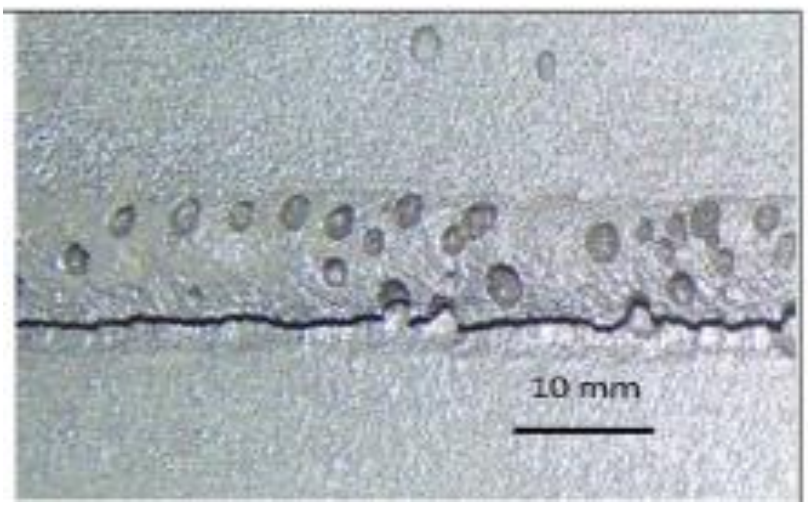

Figure 6: Corrosion of a cylindrical decanter vessel.

The failure number 6 (Fig. 7) occurred in the same equipment of failure 5, after 83 months of operation. Loss of metal (up to $3.1 \mathrm{~mm}$ ) was identified in the lower generators of the vessel, especially in the re- 
gions adjacent to the assembly welds, resulting in a reduction of the maximum allowable working pressure of the equipment. The corrosion in an acid medium was generalized, alveolar in base metal and in the welded joint. The generalized corrosion was consequence of harsh environment of $\mathrm{pH} \mathrm{1.5-2.0} \mathrm{with} \mathrm{chlorides.} \mathrm{The}$ localized corrosion observed in base metal was consequence of the ineffectiveness of the acid dosing system, and production halts without proper acid phase drainage.

The biodiesel received the acidic water and passed through the static mixer. But due to the inefficiency of the mixture, biodiesel enters the decanter as a two-phase fluid, an apolar biodiesel phase and a polar phase of acid water. In the decanter, the bottom contains glycerinated water and the top contains the heterogeneous mixture of biodiesel and acid water. Routine inspection equipment (internal inspection) identified this problem. Fragility of the equipment with reduction of its useful life occurred. Comparing failures 1 and 2 of AISI 904L SS in media of pH between 3 and 5.5 with failures 5 and 6 of AISI 904L SS in media of lower $\mathrm{pH}(1.5-2.0)$, we can conclude that these failures occurred due to a great number of variables and conditions in complex systems where sometimes $\mathrm{pH}$ does not play a major role. Time to failure was 23 and 29 months for failures 1 and 2, and failure time was 62 and 83 months for failures 5 and 6 where the steel was exposed to a more aggressive media of $\mathrm{pH}$ as lower as 1.5. Failure 1 represents a localized corrosion of AISI 904 steel in acid water of a higher $\mathrm{pH}$ than fluids associated to the failures 3 and 4 but showed the lowest failure time due to the greatest proximity to the acid injection site. In this case, the fluid provides the occurrence of steel surface regions wetted with biodiesel and regions wetted with acid water. In addition to this new parameter, the mechanism operating is very studied and involves formation of a passive film, breakdown of the passive film, growth of metastable pits which can repassivate and growth of stable pits [20-22]. Stainless steels in acid solutions containing chlorides are quite prone to pitting attack [23].

The acid environment results in the destruction of the film layer and severe pitting formation [22]. Low $\mathrm{pH}$ value of solution decreases the impedance of the film and increases the OH-/O2- ratio leading to more severe pitting corrosion [22]. The presence of welding in equipment aggravates the corrosion problems due to the possibility of occurrence of corrosion cells in the regions with different grain sizes, galvanic cells due to the difference in the composition of the consumable and the base metal, aeration and concentration cells caused by crevice, but the objective of this work is to emphasize the effect of the inefficiency of mixing the biodiesel with the acid solution in the corrosion failures.

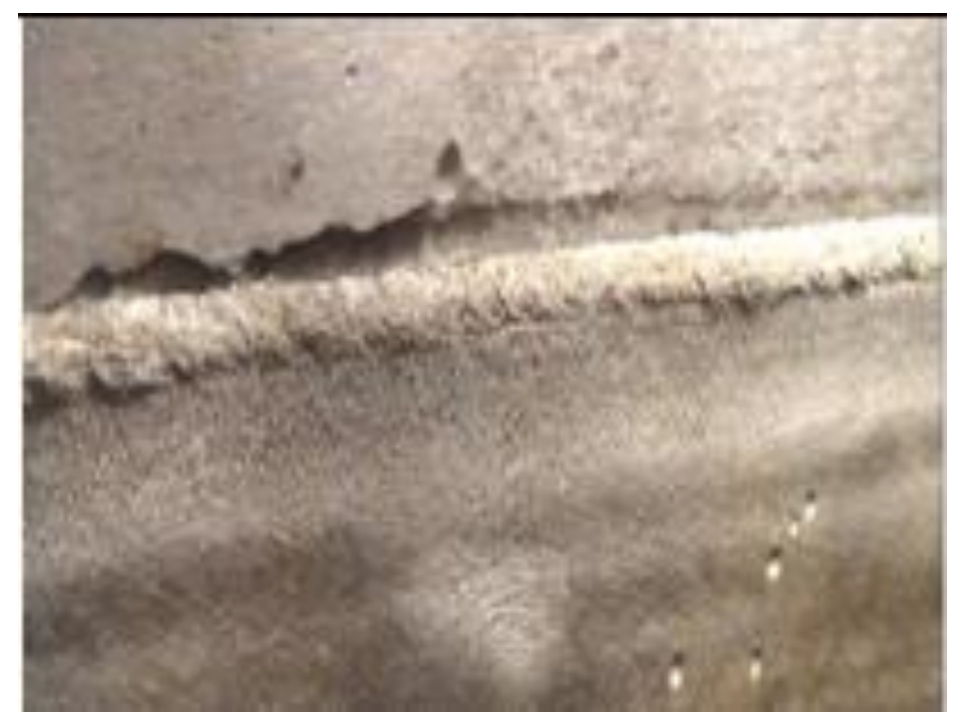

Figure 7: Corrosion in a cylindrical decanter vessel in the lower generators of the vessel, especially in the regions adjacent to the assembly welds.

Failures 7 and 8 occurred in glycerin circuit were associated to the temperature effect. The failure number 7 analyzed occurred in a shell and a SAF-2507 tube heat exchanger which raises the temperature of glycerin to $95^{\circ} \mathrm{C}$ (Figure 8). On the cold side, the fluid was processed glycerin with $25 \mathrm{wt} \% \mathrm{H} 2 \mathrm{O}$ and 7 wt.\% $\mathrm{NaCl}$, and on the hot side the fluid was $10.0 \mathrm{kgf} / \mathrm{cm}^{2}$ steam. The process parameters were $\mathrm{pH}$ of 4.5 to 5.5 ; mass flow rate of $40 \mathrm{t} / \mathrm{h}$. The glycerin temperature (cold side) was $60^{\circ} \mathrm{C}$ (input) and $95^{\circ} \mathrm{C}$ (output). The fail mode was corrosion with significant reduction of thickness of the tubes mainly in the hot side immediately 
below the mirror as shown in Fig. 8. In thermogalvanic cells, the anode is usually the hot region. According to the Nernst equation, an increase in temperature reduces the reduction potential of a half reaction [17].

Thus, the cold region with a higher reduction potential is usually the cathode in this cell [17]. The detection mode was equipment inspection routine (thickness measurement technique by IRIS - "Internal Rotary Inspection System"). The failure mechanism was electrochemical corrosion in an acid media, accelerated by the temperature gradient along the tube (thermogalvanic cell). The ineffectiveness of acid dosing system (control) and high concentration of catalyst also contributed to this failure. The consequence of failure was the equipment campaign reduction.

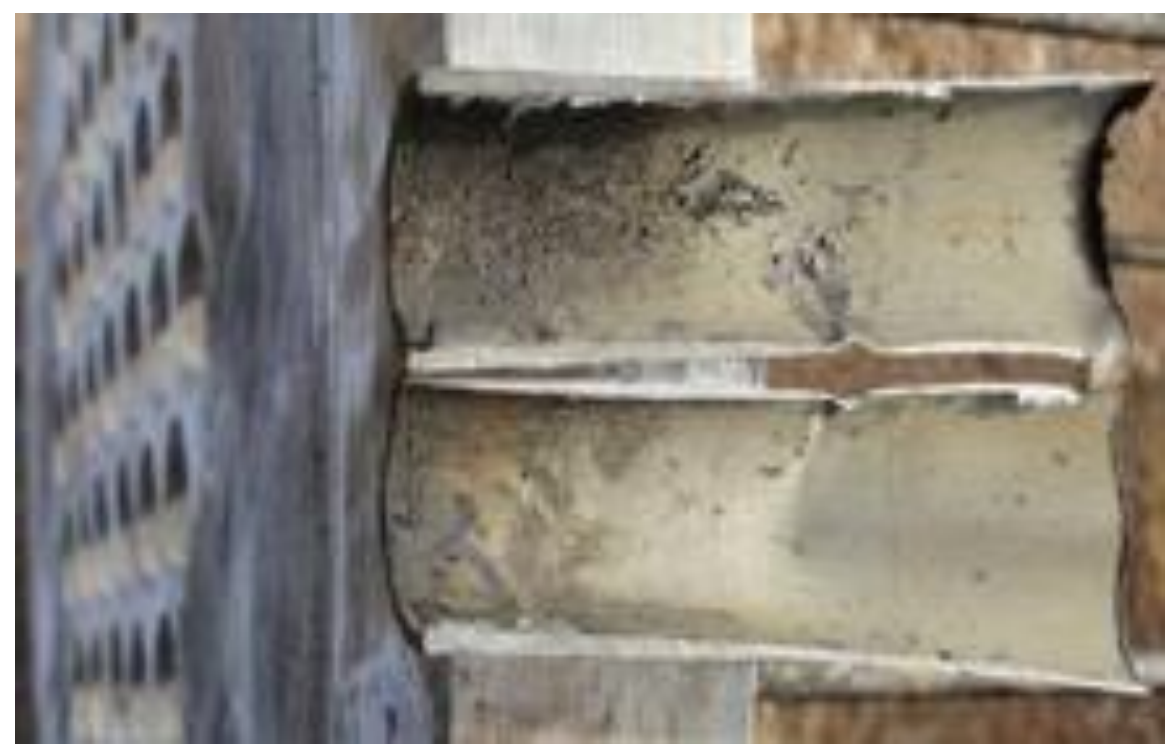

Figure 8: Corrosion in a shell and a SAF-2507 tube heat exchanger which raises the temperature of glycerin to $95^{\circ} \mathrm{C}$.

The failure number 8 was identified, after 54 months of operation, in a hull and tube type heat exchanger. The tubes are made of SAF-2507 steel, with diameter of $19.10 \mathrm{~mm}$ and thickness of $2.10 \mathrm{~mm}$, which function was to increase the glycerin temperature from $69^{\circ} \mathrm{C}$ to $95^{\circ} \mathrm{C}$, at the distillation stage, as shown in Fig. 9. Process glycerin contained 25 wt. $\%$ water and 7 wt. $\% \mathrm{NaCl}$, at $95{ }^{\circ} \mathrm{C}, \mathrm{pH}$ of $4.5-5.5$, and mass flow rate of $40 \mathrm{t} / \mathrm{h}$ (recirculation). Communication occurred between the phases of the exchanger caused by passing discontinuities (holes) in the pipes. The corrosion morphology was generalized and alveolar shape, accelerated by the significant temperature difference in the tubes, in the region near the mirror (thermogalvanic cell) [24]. The inefficiency of the acid dosing system, and high catalyst ratio also produced the corrosion failure, but this cause was more relevant in the biodiesel circuit. This failure was detected by process follow-up routine and leak testing. Contamination of the condensate system with unplanned shutdown caused loss of production. 

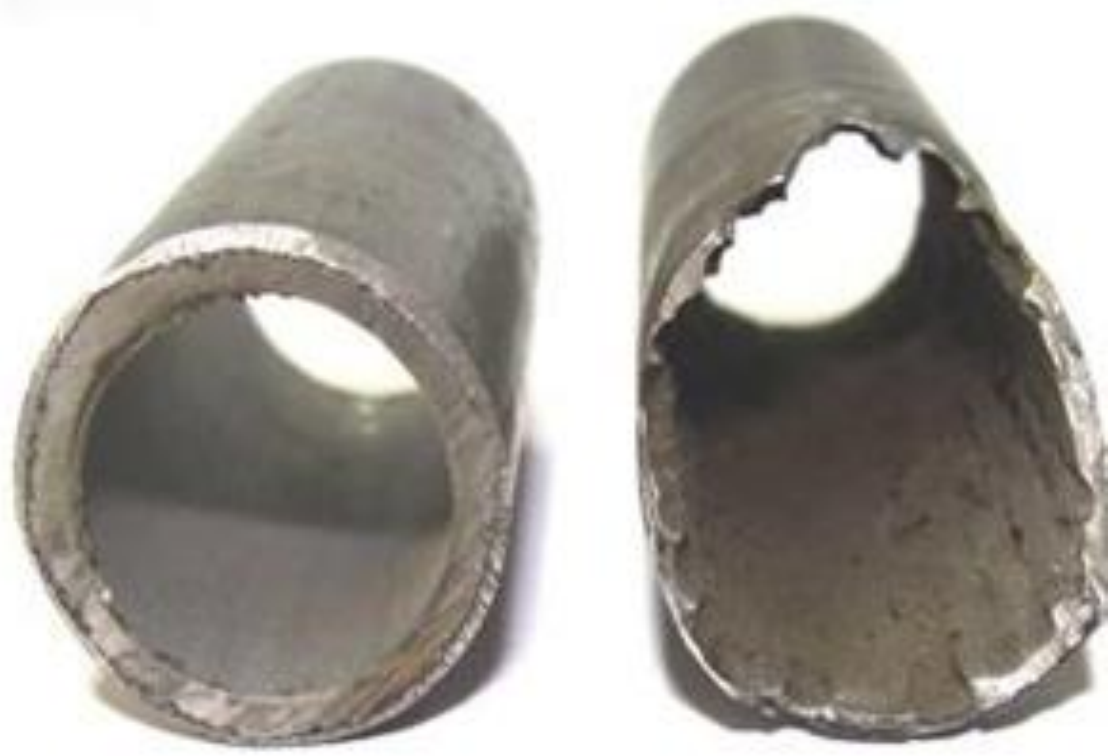

Figure 9: Corrosion in tubes of a hull and tube type heat exchanger.

Analyzing the causes of failures in the presented cases, it was observed that the ineffectiveness of the acid dosing system was related to all reported failures. Production halts without proper acid phase drainage, inefficient configuration (diagonal geometry) of the neutralization current insertion spool in the biodiesel stream, high concentration of catalyst were specific causes of failures studied.

In the biodiesel plant, AISI 304 SS was substituted by AISI 316L SS, due to the corrosiveness of medium. A recommendation is the use of nobler materials such as AISI 904L SS, duplex steels, or nickel alloy in critical points of process, such as the region of A-14 mixer and V-2006 second decanter in biodiesel circuit and the region of P-28 heat exchanger in glycerin circuit. However, this work alerts that the material specification is not sufficient to prevent corrosion failures. Technical requirements and improvements of welding procedures and acid dosage system are highly recommended such as the substitution of the diagonal geometry of acid injection by the elbow geometry by using an emissary tube.

\section{CONCLUSIONS}

Of the total analyzed failures in three biodiesel plants in Brazil, 45.5\% occurred in the biodiesel circuit and $54.5 \%$ in the glycerin circuit. Corrosion failures occurred in pipes transporting biodiesel and acid water, in a spool of acid water injection, in a static biodiesel mixer with acidic water, in a cylindrical decanter vessel, and in heat exchangers. Analyzing the causes of failures in the presented cases, it was observed that the ineffectiveness of the acid dosing system was related to all reported failures.

The poor miscibility between biodiesel and acid water generating a heterogeneous coverage of the surface of the pipelines and equipment by biodiesel and acid water, presence of galvanic cells and localized corrosion. Production halts without proper acid phase drainage, inefficient configuration (diagonal geometry) of the neutralization current insertion spool in the biodiesel stream, high concentration of catalyst were specific causes of failures studied. The material specification is not sufficient to prevent corrosion failures. Technical requirements and improvements of welding procedures and acid dosage system are highly recommended such as the substitution of the diagonal geometry of acid injection by the elbow geometry by using an emissary tube.

\section{ACKNOWLEDGMENTS}

The authors thank the Conselho Nacional de Desenvolvimento Científico e Tecnológico, CNPq.

\section{BIBLIOGRAPHY}

[1] VOJTISEK-LOM, M., MARTIN, P., MAZAC, M., "Measurement of consumption rates of viscous biofuels", Fuel v., 107, pp. 448-454, 2013. 
[2] SAN JOSÉ ALONSO, J.F., ROMERO-ÁVILA, C., SAN JOSÉ HERNÁNDEZ, L.M., et al., "Characterising biofuels and selecting the most appropriate burner for their combustion", Fuel Process Technology, v. 103, pp. 39-44, 2012.

[3] YE, F., LI, Y., YANG, Q., "Designing coordination contract for biofuel supply chain in China", Resources, Conservation and Recycling, v. 128, pp. 306-314, 2018.

[4] DALEMANS, F., MUYS, B., VERWIMP, A., et al., "Redesigning oilseed tree biofuel systems in India", Energy Policy, v. 115, pp. 631-643, 2018.

[5] MUNJUR, Md., MOULA, E., NYÁRI, J., et al., "Public acceptance of biofuels in the transport sector in Finland", International Journal of Sustainable Built Environment, v. 6, pp. 434-441, 2017.

[6] OH, Y-K., HWANG, K-R., KIM, C., et al., "Recent developments and key barriers to advanced biofuels: A short review", Bioresource Technology, v.257, pp. 320-333, 2018.

[7] KNOTHE, G., RAZON, L.F., "Biodiesel fuels", Progress in Energy and Combustion Science, v.58, pp. 36-59, 2017.

[8] ASAKUMA, Y., MAEDA, K., KURAMOCHI, H., et al., "Theoretical study of the transesterification of triglycerides to biodiesel fuel”, Fuel, v. 88, pp. 786-791, 2011.

[9] KUMAR, R., TIWARI, P., GARG, S., "Alkali transesterification of linseed oil for biodiesel production", Fuel, v. 104, pp. 553-600, 2013.

[10] WANG, W., JENKINS, P.E., REN, Z., "Heterogeneous corrosion behaviour of carbon steel in water contaminated biodiesel", Corrosion Science, v. 53, pp. 845-849, 2011.

[11] TIAN, W., DU, N., LI, S., et al., "Metastable pitting corrosion of 304 stainless steel in 3.5\% NaCl solution", Corros Sci., v.85, pp. 372-379, 2014.

[12] DU, D., CHEN, K., LU, H., ZHANG, L., et al., "Effects of chloride and oxygen on stress corrosion cracking of cold worked 316/316 L austenitic stainless steel in high temperature water", Corrosion Science, v. 110, pp. 134-142, 2016.

[13] DELAUNOIS, F., TSHIMOMBO, A., STANCIU, V., et al., "Monitoring of chloride stress corrosion cracking of austenitic stainless steel: identification of the phases of the corrosion process and use of a modified accelerated test", Corrosion Science, v. 110, pp. 273-283, 2016.

[14] FENG, X., LU, X., ZUO, Y., et al., "The effect of deformation on metastable pitting of 304 stainless steel in chloride contaminated concrete pore solution”, Corrosion Science, v. 103, pp. 223-229, 2016.

[15] ABEL, J., VIRTANEN, S., "Corrosion of martensitic stainless steel in ethanol-containing gasoline: Influence of contamination by chloride, $\mathrm{H} 2 \mathrm{O}$ and acetic acid", Corrosion Science, v. 98, pp. 318-326, 2015.

[16] FERREIRA, D.J.O., TORRES, C. E. A. S., LINS, V.F.C., et al., "Computational fluid dynamics investigation for austenitic AISI 904L stainless steel corrosion in a biodiesel stream piping", Materials and Corrosion, v. 69, pp. 266-279, 2018.

[17] McCAFFERTY, E., Introduction to Corrosion Science, New York, Springer-Verlag, 2010.

[18] HENDERSON, J.D., EBRAHIMI, N., DEHNAVI, V., et al., "The role of internal cathodic support during the crevice corrosion of Ni-Cr-Mo alloys", Electrochimica Acta, v. 283, pp.1600-1608, 2018.

[19] FRANKEL, G.S., LI, T., SCULLY, J.R., "Localized Corrosion: Passive Film Breakdown vs Pit Growth Stability”, Journal of Electrochemical Society, v. 164, C180-C181, 2017.

[20] ORGAN, L., SCULLY, J.R., MIKHAILOV, A.S., et al., "A spatiotemporal model of interactions among metastable pits and the transition to pitting corrosion”, Electrochimica Acta, v.51, pp. 225-241, 2005.

[21] SCHEINER, S., HELLMICH, C., "Stable pitting corrosion of stainless steel as diffusion-controlled dissolution process with a sharp moving electrode boundary", Corrosion Science, v. 49, pp. 319-346, 2007.

[22] JIN, Z.H., GE, H.H., LIN, W. W., et al., "Corrosion behaviour of 316L stainless steel and anti-corrosion materials in a high acidified chloride solution", Applied Surface Science, v. 322, pp. 47-56, 2014.

[23] SAITOU, M., OSHIKAWA, W., ISHIKAWA, T., "Anomalous dimension in pitting corrosion of SUS304 in a NaCl solution", Corrosion Science, v. 44, pp. 1469-1475, 2002.

[24] ALZAHRANI, H. A. H., BLACK, J.J., GOONETILLEKE, D., et al., "Combining thermogalvanic corrosion and thermogalvanic redox couples for improved electrochemical waste heat harvesting", Electrochemistry Communications, v. 58, pp. 76-79, 2015. 


\section{ORCID}

Carlos Eduardo de Almeida Souza Torres

Thalys Eduardo dos Santos

https://orcid.org/0000-0002-8740-9268

Vanessa de Freitas Cunha Lins

https://orcid.org/0000-0003-3382-8878

https;//orcid.org/0000-0002-6357-9553 